\section{Regulation of calcium phosphate formation by amelogenins under physiological conditions}

Kwak S-Y, Green S, Wiedemann-Bidlack FB, Beniash E, Yamakoshi Y, Simmer JP, Margolis HC. Regulation of calcium phosphate formation by amelogenins under physiological conditions.

Eur J Oral Sci 2011; 119 (Supp. 1): 103-111. (C) 2011 Eur J Oral Sci

Amelogenin is essential for proper enamel formation. The present in vitro study extends our previous work at low $(10 \mathrm{mM})$ ionic strength (IS) by examining the effect of amelogenin on mineralization under higher $(162 \mathrm{mM})$ IS conditions found in developing enamel. Full-length phosphorylated (P173) and non-phosphorylated (rP172) amelogenins were examined, along with $\mathrm{P} 148$ and rP147 that lack the hydrophilic Cterminus. Calcium phosphate formation was assessed by $\mathrm{pH}$ change, while the minerals formed were characterized using transmission electron microscopy (TEM) and Fourier transform infrared spectroscopy. Amelogenin self-assembly was also studied using dynamic light scattering and TEM. The results indicate that IS does not influence the effects of rP147, rP172, and P173 on mineralization. However, in contrast to the findings for low IS, where both P173 and P148 stabilize initially formed amorphous calcium phosphate (ACP) nanoparticles for $>1 \mathrm{~d}$, elongated hydroxyapatite crystals were observed after $24 \mathrm{~h}$ using P148 at high IS, unlike that seen with P173. Differences in self-assembly help explain these findings, which suggest that P173 and P148 may play different roles in regulating enamel mineral formation. The present data support the notion that proteolytic processing of P173 is required in vivo to induce the transformation of initial ACP phases to apatitic enamel crystals.

\section{Seo-Young Kwak ${ }^{1,2}$, Samantha Green $^{3}$, Felicitas B. Wiedemann- Bidlack $^{1,2}$, Elia Beniash ${ }^{4}$, Yasuo Yamakoshi $^{5}$, James P. Simmer ${ }^{5}$, Henry C. Margolis ${ }^{1,2}$}

${ }^{1}$ Department of Biomineralization, The Forsyth Institute, Cambridge, MA; ${ }^{2}$ Department of Developmental Biology, Harvard School of Dental Medicine, Boston, MA; ${ }^{3}$ Department of Biochemistry, Simmons College, Boston, MA;

${ }^{4}$ Department of Oral Biology, University of Pittsburgh, Pittsburgh, PA; ${ }^{5}$ Department of Biologic and Materials Sciences, University of Michigan, Ann Arbor, MI, USA

\section{Henry C. Margolis, Department of Biomineralization, The Forsyth Institute, 245} First Street, Cambridge, MA 02142, USA

Telefax: +1-617-8928432

E-mail: hmargolis@forsyth.org

Key words: amelogenin; enamel; hydroxyapatite; ionic strength; mineralization

Accepted for publication October 2011
Dental enamel, the hardest and most mineralized tissue in the human body, makes up the outer layer of tooth crowns. Although mature enamel contains $95 \mathrm{wt} \%$ carbonated apatite and $<1-2 \%$ organic material and water, the forming early secretory enamel consists of approximately $30 \mathrm{wt} \%$ mineral, $20 \mathrm{wt} \%$ organic matrix (protein), and $50 \mathrm{wt} \%$ water $(1,2)$. The organic matrix of developing enamel is believed to regulate the shape and organization of forming mineral crystals $(3,4)$. The organic matrix is composed predominantly of amelogenins, which make up over $90 \%$ of the enamel matrix. A number of in vitro studies have suggested that amelogenin plays essential roles in enamel formation, especially with respect to regulating the size, shape, and ordered arrangement of mineral particles (5-8). One biomineralization strategy that has received significant attention in recent years is mineralization via transient precursor phases. The presence of transient mineral phases, particularly amorphous calcium phosphate (ACP) in vertebrate mineralized tissues (9), has been a subject of some controversy (10-12), although recent data strongly support its presence in developing enamel (13). Robinson et al. (14) previously showed, using freeze-fracture techniques, chains of spherical particles (50 $\mathrm{nm}$ in diameter) in forming enamel. These authors hypothesized that the early mineral particles which organize into chains and elongated ribbon-like crystals in the early secretory enamel form via the fusion of spherical particles containing ACP and protein, although no direct evidence for the presence of ACP was obtained. It was further suggested that the proteolytic cleavage of the enamel proteins triggers the fusion of the mineral particles and subsequent mineral phase transformation (15, 16).

Recently, we have obtained new insight into the role of the highly conserved C-terminal domain of amelogenin and the single phosphate group on serine 16 of porcine amelogenins in regulating spontaneous calcium phosphate formation in vitro $(8,17)$. In particular, we found that both full-length (P173) and truncated (P148) native phosphorylated amelogenins can stabilize ACP for long periods of time $(>1 \mathrm{~d})$ in vitro. In contrast, the recombinant non-phosphorylated full-length amelogenin (rP172) transiently stabilizes ACP and guides its transformation into ordered bundles of hydroxyapatite (HA) crystals, while a non-phosphorylated truncated form 
(rP147) that lacks the hydrophilic C-terminus had little to no effect on mineralization. Similar findings were recently obtained using phosphorylated and non-phosphorylated structural variants of the leucine-rich amelogenin peptide (LRAP) $(18,19)$, confirming the importance of both the hydrophilic C-terminus and the single phosphate group in regulating mineral formation.

The present study was carried out to extend our previous work by examining the effect of amelogenin on mineralization under experimental conditions that more closely reflect those found in vivo during enamel formation. More specifically, the present studies were performed under the physiological ionic strength (IS) condition (162 mM) found in secretory enamel fluid (20), which is substantially greater than that $(10 \mathrm{mM})$ used in our previous studies $(8,17)$. The effect of primary structure on mineralization in vitro was studied using native phosphorylated (P173) and recombinant nonphosphorylated (rP172) full-length amelogenin, along with native (P148) and recombinant (rP147) forms of a prominent amelogenin cleavage product that lacks the hydrophilic C-terminus (Fig. 1). Concurrently, we examined the effect of IS on amelogenin self-assembly in the presence of calcium.

\section{Material and methods}

\section{Protein preparation}

The full-length native porcine amelogenin P173 and its predominant cleavage product $\mathrm{P} 148$ were isolated and purified from developing tooth buds, as previously described (21). Recombinant versions of these proteins, rP172 and $\mathrm{rP} 147$, were derived from bacteria and purified as reported previously (22). As shown in Fig. 1, the recombinant proteins lack a single phosphate group at serine 16 (S-16) and an N-terminal methionine, both of which are present in the native amelogenins. P148 and rP147 also lack 25 Cterminal amino acids, including the hydrophilic C-terminal domain. Lyophilized amelogenins were weighed and dissolved in distilled deionized water (DDW) at room temperature to yield stock solutions of $5 \mathrm{mg} \mathrm{ml}^{-1}$. Stock solutions had initial $\mathrm{pH}$ values below 4 and were stored for at least $24 \mathrm{~h}$ at $4^{\circ} \mathrm{C}$ to ensure complete dissolution. Complete dissolution of protein samples was confirmed using dynamic light scattering (DLS), as described below, that showed particle sizes between 1 and $2 \mathrm{~nm}$, consistent with the presence of monomers or dimers. Protein stock solutions were centrifuged $\left(10,900 \times g\right.$, at $4^{\circ} \mathrm{C}$ for $\left.20 \mathrm{~min}\right)$ just prior to use to remove dust and other extraneous particulate matter. All other solutions were filtered before use (through a $0.22 \mu \mathrm{m}$ filter).

\section{Mineralization studies}

Aliquots of calcium and $\mathrm{pH}$-adjusted phosphate solution $(\sim \mathrm{pH} 11.2)$ were sequentially added to protein solutions, as previously reported (8). The solution was then quickly adjusted to a final value of $\mathrm{pH} 7.4$ at $37^{\circ} \mathrm{C}$ with small quantities of $\mathrm{KOH}$ to yield final concentrations of $2.5 \mathrm{mM}$ calcium, $1.5 \mathrm{mM}$ phosphate and $2 \mathrm{mg} \mathrm{ml}^{-1}$ of amelogenin (final volume $=0.06 \mathrm{ml}$ ). Unlike the previous research (8), the present study was carried out at a higher IS with the addition of $\mathrm{KCl}$ to both the calcium and phosphate solutions to yield a final $\mathrm{KCl}$ concentration of $150 \mathrm{mM}$. The initial solution was designed to mimic the physiological IS found in secretory enamel (20), with a nominal IS of $162 \mathrm{mM}$. The $\mathrm{pH}$ of each experimental solution, maintained at $37^{\circ} \mathrm{C}$ in a constant-temperature water bath, was monitored continuously using a micro-combination $\mathrm{pH}$ electrode (MI-410; Microelectrodes, Bedford, NH, USA). Each experiment was conducted using duplicate samples in separate tubes, with the second tube being used for transmission electron microscopy (TEM) analyses, as described below. Each experiment was repeated 6-10 times.

\section{Dynamic light scattering}

Dynamic light scattering studies were carried out to investigate the effect of calcium on protein assembly at both low IS and high IS at $\mathrm{pH}$ 7.3-7.5. The $\mathrm{pH}$ adjustment of each protein solution was made with $\mathrm{KOH}$, at $25^{\circ} \mathrm{C}$. The final concentration of protein was $2 \mathrm{mg} \mathrm{ml}^{-1}$. In order to study the effect of calcium ions on amelogenin self-assembly, calcium chloride was added to yield a final concentration of $2.5 \mathrm{mM}$ calcium before $\mathrm{pH}$ adjustment (IS $=7.5 \mathrm{mM}$ ). In parallel experiments, the IS was adjusted to $162 \mathrm{mM}$ by adding $\mathrm{KCl}$. Dynamic light scattering measurements of sample solutions were made immediately after preparation using a $12 \mu \mathrm{l}$ aliquot placed in a specially designed quartz cuvette. Measurements were made as previously reported (17) using a DynaPro MSXTC/12 DLS instrument (Wyatt Technology Inc., Santa Barbara, CA, USA). Four consecutive measurements were made at 5-min intervals at a

$$
\begin{aligned}
& \text { P173 MPLPPHPGHPGYINFS }{ }^{\mathbf{P}} \text { YEVLTPLKWYQNMIRHPYTSYGYEPMGGWLHHQIIPVVSQQTPQ } \\
& \text { SHALQPHHHIPMVPAQQPGIPQQPMMPLPGQHSMTPTQHHQPNLPLPAQQPFQPQP } \\
& \text { VQPQPHQPLQPQSPMHPIQPLLPQPPLPPMFSMQSLLPDLPLEAWPATDKTKREEVD } \\
& \text { C-Terminus } \\
& \text { P148 MPLPPHPGHPGYINFS }{ }^{\mathbf{P}} \text { YEVLTPLKWYQNMIRHPYTSYGYEPMGGWLHHQIIPVVSQQTPQ }
\end{aligned}
$$

Fig. 1. Amino acid sequences of native (P) and recombinant (rP) porcine amelogenins used in the present study. The single phosphorylation at serine 16 in P173 and P148 is highlighted and indicated in bold. The hydrophilic C-terminal domain that is absent in rP147 and P148 is also highlighted and indicated in bold. The most hydrophilic portion of the C-terminal domain is underlined. 
constant temperature of $25^{\circ} \mathrm{C}$ with each measurement comprised of 20 acquisitions of $5 \mathrm{~s}$ each. The size [hydrodynamic radius $\left(R_{\mathrm{H}}\right)$ ] of amelogenin assemblies was determined using Dynamics V6.3.4.0 software. The formation of very large aggregates (in the micrometer range) or gel-like phases at the protein concentrations used is indicated by a sharp jump in the scattering signal intensity to values above the detection limit of the instrument (referred to hereafter as off-scale values), preventing measurement of particle sizes.

\section{TEM analysis}

Aliquots $(5 \mu \mathrm{l})$ were taken immediately from protein solution samples used for DLS assembly experiments, or at specified time-points from mineralization experiments, and placed on carbon-coated copper $(\mathrm{Cu})$ grids (Electron Microscopy Sciences, Hatfield, PA, USA). Samples from mineralization experiments were left at room temperature for $30 \mathrm{~s}$, blotted on Grade 1 Whatman filter paper (Cat. No. 10001-329), rinsed with filtered DDW, and air dried. Duplicate grids were prepared from a minimum of three different experiments. For protein-assembly studies, duplicate sample grids were incubated at $37^{\circ} \mathrm{C}$ for $20 \mathrm{~min}$ in a humidity chamber, to simulate conditions used for DLS studies. Samples were then blotted, rinsed with filtered DDW, air dried, and then negatively stained with $1 \%$ filtered phospho-tungstic acid (PTA) at pH 7.2. Images were obtained in bright field and/or selected area electron diffraction (SAED) modes using a JEOL 1200 TEM microscope (JEOL, Peabody, MA, USA) at $100 \mathrm{kV}$ and captured by an AMT CCD camera (AMT, Danvers, MA, USA). In some cases, contrast and brightness of images were adjusted using Adobe Photoshop 12.0 to enhance clarity. For comparative purposes, an SAED analysis of the carbon-coated $\mathrm{Cu}$ grid is presented in Fig. S3A.

\section{Fourier transform-infrared spectroscopy}

Fourier transform-infrared (FT-IR) analyses of the final mineral products were carried out to confirm the SAED findings. Twenty-four-hour samples from selected mineralization experiments were concentrated, placed on potassium bromide ( $\mathrm{KBr}$ ) sheets (KBr IR Card; International Crystal Laboratories, Garfield, NJ, USA), and air-dried. The FT-IR spectra $\left(4000-450 \mathrm{~cm}^{-1}\right)$ of samples were then recorded using a Multiscope FT-IR microscope (Perkin-Elmer, San Jose, CA, USA) in the reflectance mode, as reported (8). Owing to the extremely small amounts of mineral formed in our mineralization system with a final volume of $60 \mu \mathrm{l}$, however, the FT-IR spectra of mineral products obtained in this manner became extremely noisy below $600 \mathrm{~cm}^{-1}$. Hence, absorption bands in this region could not be used to aid in mineral phase characterization. Routinely, 128 accumulated scans and $4 \mathrm{~cm}^{-1}$ resolution were used.

\section{Results}

\section{Effect of high-IS condition on spontaneous mineralization}

The effect of physiological IS (i.e. IS $=162 \mathrm{mM}$ ) on in vitro mineralization was investigated. The overall behavior of spontaneous calcium phosphate precipitation was monitored via changes in $\mathrm{pH}$ over $24 \mathrm{~h}$ (Fig. 2) or $48 \mathrm{~h}$ (data not shown). In the absence of protein
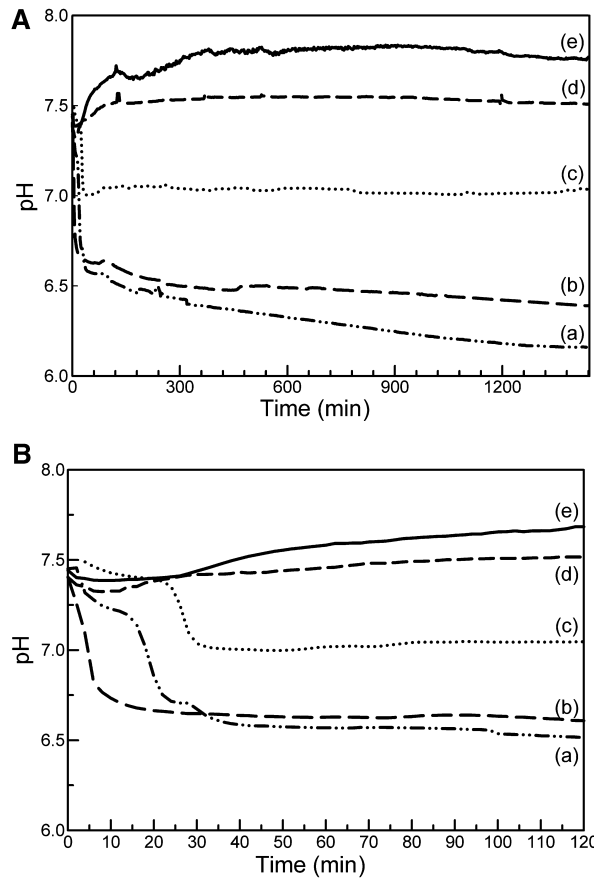

Fig. 2. Changes in $\mathrm{pH}$ as a function of time observed during mineralization experiments under high ionic strength (IS $=162 \mathrm{mM}$ ) conditions over $24 \mathrm{~h}$ (A) in the absence (a) and presence of rP147 (b), rP172 (c), P148 (d), and P173 (e). Changes in $\mathrm{pH}$ are presented in an expanded scale (B) for better clarity. Similar results were obtained for multiple repeats $(n=8-10)$.

(control), a slow decrease from around $\mathrm{pH} 7.4$ to $\mathrm{pH} 7.2$ was observed during the first $20 \mathrm{~min}$, followed by a more rapid decrease to values just below pH 6.7 [Fig. 2B, curve (a)]. The $\mathrm{pH}$ values then dropped slowly during the remainder of the $24-\mathrm{h}$ period to about $\mathrm{pH} 6.2$ [Fig. $2 \mathrm{~A}$, curve (a)]. During the initial slow phase in $\mathrm{pH}$ change, seen until 20 min [Fig. 2B, curve (a)], spherical particles, consistent with ACP morphology $(23,24)$, were observed by TEM (Fig. 3A). The broad diffuse SAED ring pattern observed is consistent with that for ACP, and nearly identical in appearance to those reported in other studies (8, 13, 25-28). As shown in Fig. S3B, the observed SAED pattern (Fig. 3A) was essentially identical to that obtained for synthetic ACP. These results are in agreement with those of previous studies conducted under low-IS conditions $(8,17)$. Corresponding to the marked decrease in $\mathrm{pH}$ [Fig. 2, curve (a)], small crystals began to emerge by $30 \mathrm{~min}$ (Fig. 3B). After $1 \mathrm{~h}$, only randomly arranged, thin, plate-like rhombohedral HA crystals or agglomerates of HA crystals were observed (Fig. 3C,D). Mineral phase identification was again based on SAED (Fig. 3C,D insets) and also by FT-IR analyses of 24-h samples [Fig. S1, (e)].

In the presence of the full-length recombinant amelogenin, rP172 [Fig. 2, curve (c)], a similar change in $\mathrm{pH}$ with time was also observed, following a slightly longer induction period of $\sim 30 \mathrm{~min}$, although the $\mathrm{pH}$ value did not drop below $\mathrm{pH} 7$ during the $24-\mathrm{h}$ period. Transmission electron microscopy and SAED analyses of samples containing $\mathrm{rP} 172$ also revealed the initial presence of nano- 


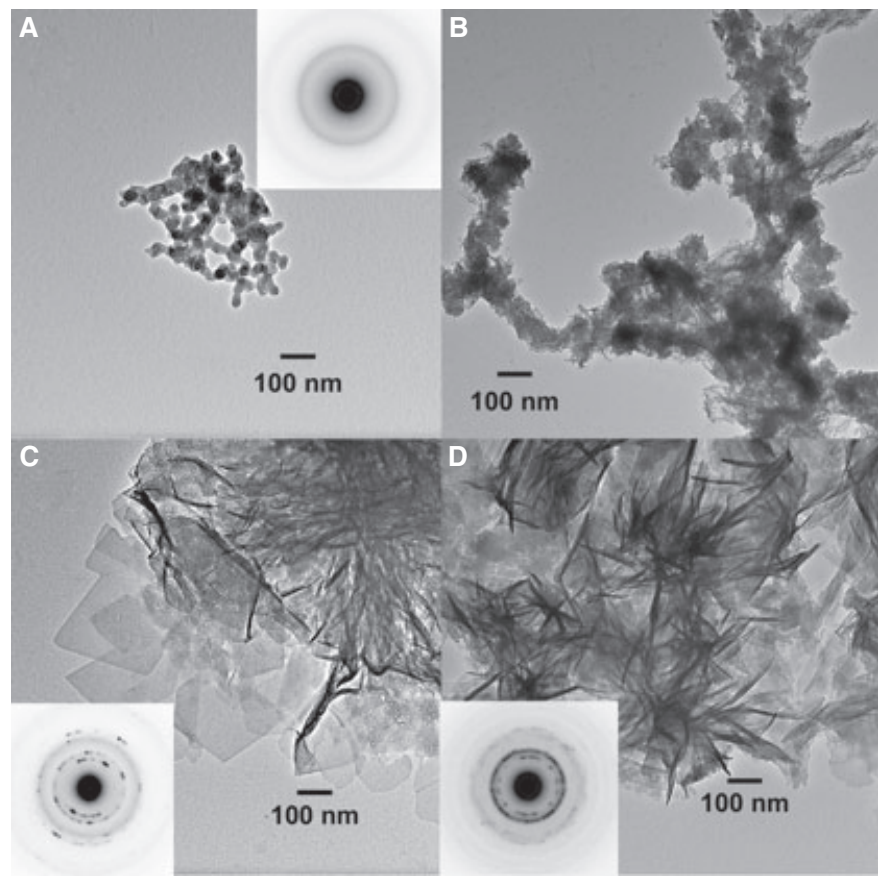

Fig. 3. Transmission electron microscopy (TEM) and selected area electron diffraction (SAED) (insets) analyses of mineral phases formed during mineralization experiments in the absence of protein (control) at high ionic strength: $10 \mathrm{~min}(\mathrm{~A}), 30 \mathrm{~min}(\mathrm{~B}), 1 \mathrm{~h}(\mathrm{C})$, and $24 \mathrm{~h}(\mathrm{D})$. The broad and diffuse SAED ring pattern seen at $10 \mathrm{~min}(\mathrm{~A})$ is consistent with that of amorphous calcium phosphate (ACP) (see the Supporting information), while the presence of discrete diffraction spots and sharp rings seen at $1 \mathrm{~h}(\mathrm{C})$ and at $24 \mathrm{~h}$ (D) are consistent with those of randomly arranged hydroxyapatite (HA) crystals.

meter-sized ACP particles at $\sim 15$ min (Fig. 4A, inset). In general, these particles were smaller than those initially seen in the control $[44 \pm 12 \mathrm{~nm}(n=41)$ at $5 \mathrm{~min}]$, having diameters of $9 \pm 2 \mathrm{~nm}(n=45)$ at $10 \mathrm{~min}$. At $1 \mathrm{~h}$ (Fig. 4B), small nanoparticles were seen to align and become closely associated to form needle-like particles. After $24 \mathrm{~h}$, multiple bundles of aligned needle-like crystals $[1=178 \pm 44 \mathrm{~nm}(n=45)]$ were consistently seen. Selected area electron diffraction analysis of an isolated bundle exhibited narrow arcs corresponding to 002 and 004 reflections (Fig. 4C, inset) oriented along the long axis of the bundle. The SAED patterns indicate that the thin crystals were elongated in the [001] direction and organized into bundles with their crystallographic $c$-axes preferentially oriented in near-parallel arrangement. The SAED results were again consistent with the formation of HA, as confirmed by FT-IR [Fig. S1, (b)].

Recombinant amelogenin that lacks the $25 \mathrm{C}$-terminal amino acids (rP147), however, showed an almost immediate decrease in $\mathrm{pH}$ [Fig. 2, curve (b)], unlike that observed for the control and the other protein-containing samples. In addition, the $\mathrm{pH}$ drop observed in the presence of rP147 leveled off after $30 \mathrm{~min}$ and at a slightly higher $\mathrm{pH}$ value than that observed in the control. At $10 \mathrm{~min}$, small nanoparticles $(58 \pm 19 \mathrm{~nm}$; $n=144$ ) of ACP were observed (Fig. 4D), which were similar in size than those found in the control. The results shown in Fig. 4E indicate that at $1 \mathrm{~h}$, mineralization in the presence of rP147 appears to take place outside the observed protein aggregates. Based on TEM, SAED, and FT-IR [Fig. S1, (a)] analyses of 24-h sam- ples, randomly arranged plate-like HA crystals were found (Fig. 4F, inset), that were similar in these respects to those seen in the control and at low IS (8).

With added P148 or P173, relatively little $\mathrm{pH}$ change was observed up to $24 \mathrm{~h}$ [Fig. 2, curves (d) and (e), respectively] and even longer, up to $48 \mathrm{~h}$ (data not shown), in a manner quite similar to that seen under lowIS conditions $(8,17)$. At the beginning of the reaction, the $\mathrm{pH}$ decreased slightly ( $\sim 0.1 \mathrm{pH}$ units) during the first $30 \mathrm{~min}$ and then slowly increased to almost the same initial $\mathrm{pH}$ value (for P148), or somewhat above the initial $\mathrm{pH}$ value (for P173), which then remained relatively constant for up to $24 \mathrm{~h}$, as shown (Fig. 2A). The TEM images exhibited monodispersed particles and/or networks of ACP at all time-points noted from $10 \mathrm{~min}$ to $9 \mathrm{~h}$, consistent with the lack of $\mathrm{pH}$ change observed during the mineralization experiments in the presence of either P148 (Fig. 5D,E) or P173 (Fig. 5A,B). Unexpectedly, elongated needle-like HA particles were consistently observed after $24 \mathrm{~h}$ in the presence of P148 under these high-IS conditions (e.g. Fig. 5F). However, the mineral formed varied greatly with respect to size and orientation, as shown in Fig. S2. In some cases, crystals appeared to form oriented mineral bundles. These latter forms were, at times, directly associated with protein masses. After $48 \mathrm{~h}$, some very dense bundles of crystals could be seen. Nevertheless, nanoparticles of ACP were also seen in both 24- and 48-h samples with P148. In sharp contrast to these findings, in the presence of P173, networks of very small amorphous particles were almost exclusively observed throughout the 24-h (Fig. 5A-C) 


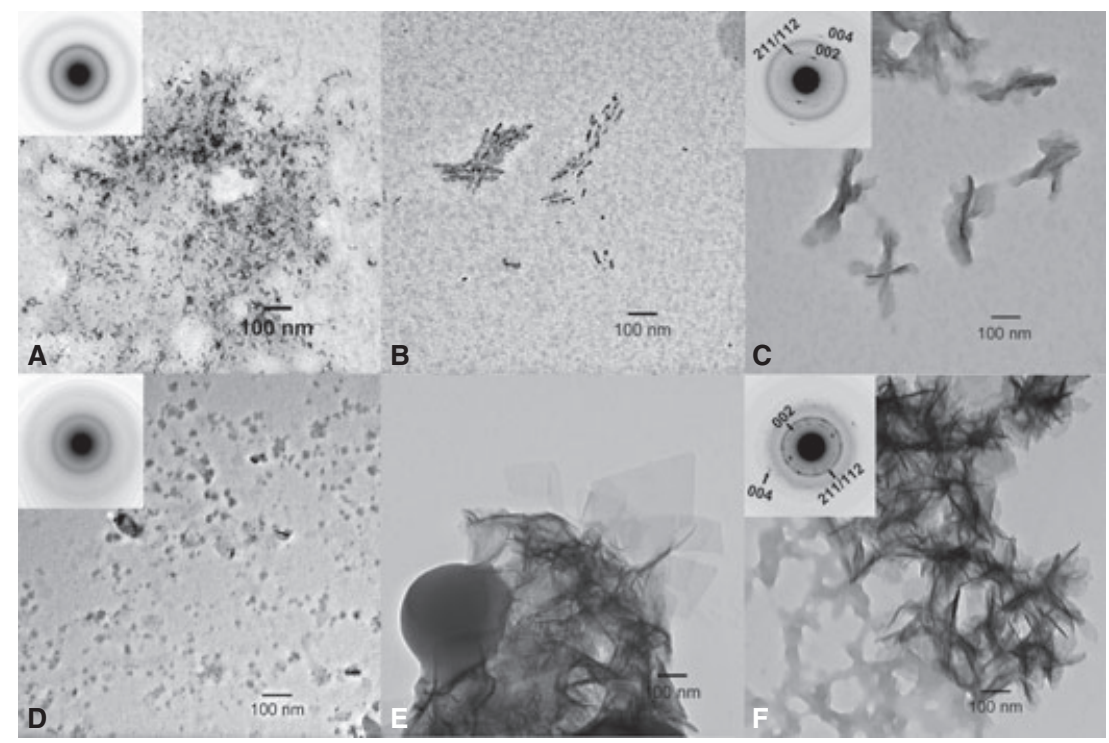

Fig. 4. Transmission electron microscopy (TEM) and selected area electron diffraction (SAED) (insets) analyses of mineral phases formed during mineralization experiments in the presence of $\mathrm{rP1} 12(\mathrm{~A}-\mathrm{C})$ and $\mathrm{rP} 147(\mathrm{D}-\mathrm{F})$ at high ionic strength: $10 \mathrm{~min}(\mathrm{~A}, \mathrm{D}), 1 \mathrm{~h}$ $(\mathrm{B}, \mathrm{E})$, and $24 \mathrm{~h}(\mathrm{C}, \mathrm{F})$. Changes in mineral shape, phase, and organization based on SAED patterns are discussed in the text.

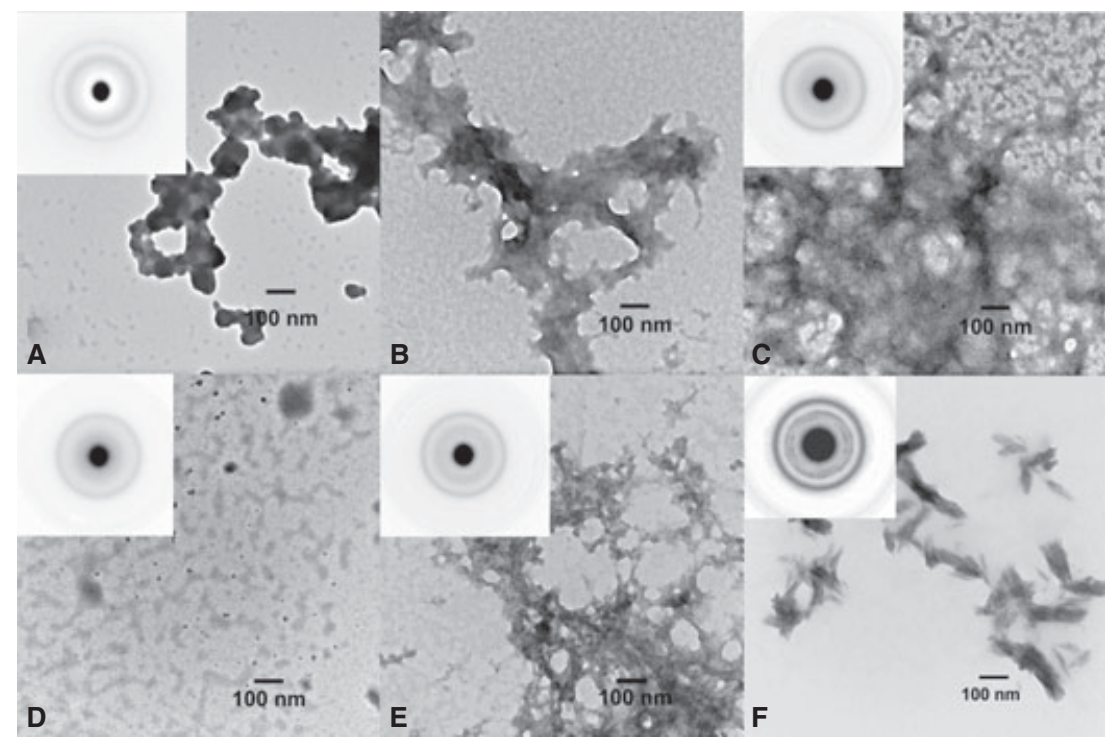

Fig. 5. Transmission electron microscopy (TEM) and selected area electron diffraction (SAED) analyses of mineral phases formed during mineralization experiments in the presence of P173 [10 min (A), $9 \mathrm{~h}(\mathrm{~B})$, and $24 \mathrm{~h}(\mathrm{C})]$ and P148 [10 min (D), $9 \mathrm{~h}(\mathrm{E})$, and $24 \mathrm{~h}$ (F)] at high ionic strength. Changes in mineral shape, phase, and organization, based on SAED patterns are discussed in the text.

and 48 -h periods. Only in rare cases were a few HA particles seen along with the prevalent networks of amorphous mineral particles. Selected area electron diffraction (Fig. 5) and FT-IR (Fig. S1) analyses confirmed the noted differences in the nature of the mineral phases formed in the presence of P173 and P148.

\section{Effect of calcium and IS on amelogenin assembly}

At $\mathrm{pH} 7.3-7.5$ at $25^{\circ} \mathrm{C}$, DLS measurements of amelogenins in the absence and presence of $2.5 \mathrm{mM} \mathrm{Ca}$ ions were performed at IS values of $7.5 \mathrm{mM}$ and $162 \mathrm{mM}$, as summarized in Table 1. Consistent with our previous findings (17), the DLS results indicated that full-length amelogenins rP172 and P173 formed small and similarly sized nanoparticles under these conditions, with mean $R_{\mathrm{H}}$ values between 11 and $15 \mathrm{~nm}$ at both low IS and high IS. The addition of $2.5 \mathrm{mM}$ calcium, however, resulted in notable changes in particle sizes $\left(R_{\mathrm{H}}\right)$ for the full-length amelogenins, P173 and rP172, at low IS, but not at high IS. For P173, while the $R_{\mathrm{H}}$ values increased to off-scale values upon the addition of calcium at low IS, small (13$14 \mathrm{~nm}$ ) monodispersed nanoparticles were still observed under high-IS conditions, as previously found for P173 in the absence of calcium under both IS conditions (17). Although rP172 particle sizes also increased considerably 
Table 1

Summary of the range of particle sizes determined by dynamic light scattering $(D L S)^{*}$

\begin{tabular}{lcclll}
\hline & & \multirow{2}{*}{$\begin{array}{c}\text { Ionic } \\
\text { strength }\end{array}$} & \multicolumn{2}{l}{ Hydrodynamic radius $\left(R_{\mathrm{H}}\right)(\mathrm{nm})$} \\
\cline { 5 - 6 } Samples $^{\dagger}$ & $\mathrm{pH}$ & $(\mathrm{mM})$ & $\mathrm{No} \mathrm{Ca}^{2+}$ & $2.5 \mathrm{mM} \mathrm{Ca}^{2+}$ \\
\hline P173 & 7.46 & 7.5 & $\sim 11$ & Off-scale** \\
& 7.30 & 162 & $11-15$ & $13-14$ \\
rP172 & 7.37 & 7.5 & $\sim 11$ & $42\left(74 \%^{\star}\right)-117\left(26 \% \%^{\ddagger}\right)$ \\
& 7.40 & 162 & $13-15$ & $13-15$
\end{tabular}

*As discussed in the text, rP147 and P148 exhibited off-scale scattering under similar experimental conditions in the absence and presence of added calcium.

**Above detection limit (see Material and Methods).

†rotein samples were at $2 \mathrm{mg} \mathrm{ml}^{-1}(n=3)$.

$\$ \%$ mass.

with added calcium at low IS, DLS results did not go offscale, but revealed two populations of larger particles with mean $R_{\mathrm{H}}$ values of $42 \mathrm{~nm}$ and $117 \mathrm{~nm}$. In contrast to that seen for the full-length amelogenins, both native (P148) and recombinant (rP147) truncated forms of amelogenin studied exhibited off-scale DLS behavior in the absence and presence of calcium under both low-IS and high-IS conditions.

The TEM analyses of aliquots of identical samples used in the DLS studies provided additional insight of the effect of calcium on protein assembly at different IS values. As seen by DLS (Table 1), TEM findings obtained in the presence of calcium (Fig. 6) similarly indicate that samples of P173 and rP172 are more aggregated at low IS (i.e. $7.5 \mathrm{mM}$ ) than at high IS (i.e. $162 \mathrm{mM}$ ). Large, densely packed aggregates of smaller assemblies of P173 (Fig. 6A) were clearly observed at low IS in the presence of calcium, whereas rather isolated chain-like assemblies were seen at high IS (Fig. 6B), under the same experimental conditions. rP172 exhibited the same tendency seen with P173, although, consistent with DLS findings, smaller, densely packed spherical aggregates of rP172 assemblies (Fig. 6C) were observed at low IS, in comparison with that seen for P173. At high IS, as seen with P173, rP172 similarly exhibited substantially less aggregated chain-like assemblies in the presence of calcium. In general, TEM analyses revealed that both of the truncated amelogenins, P148 (Fig. 6E,F) and rP147 (Fig. 6G,H), were much more highly aggregated and formed relatively large globular structures at both low and high IS in the presence of calcium, unlike the structures seen for either of the full-length proteins. However, the assembly of P148 changed significantly from greater than micron-sized spherical aggregates at low IS (Fig. 6E) to notably smaller aggregates $(\sim 300 \mathrm{~nm})$ at high IS (Fig. $6 \mathrm{~F})$ in the presence of calcium. Nevertheless, at high IS with added calcium, P148 and rP147 appear to be much more aggregated than either rP172 or P173, consistent with DLS findings (Table 1).

\section{Discussion}

Previously $(8,17)$, we showed that native full-length amelogenin, P173, and its proteolytic cleavage product,
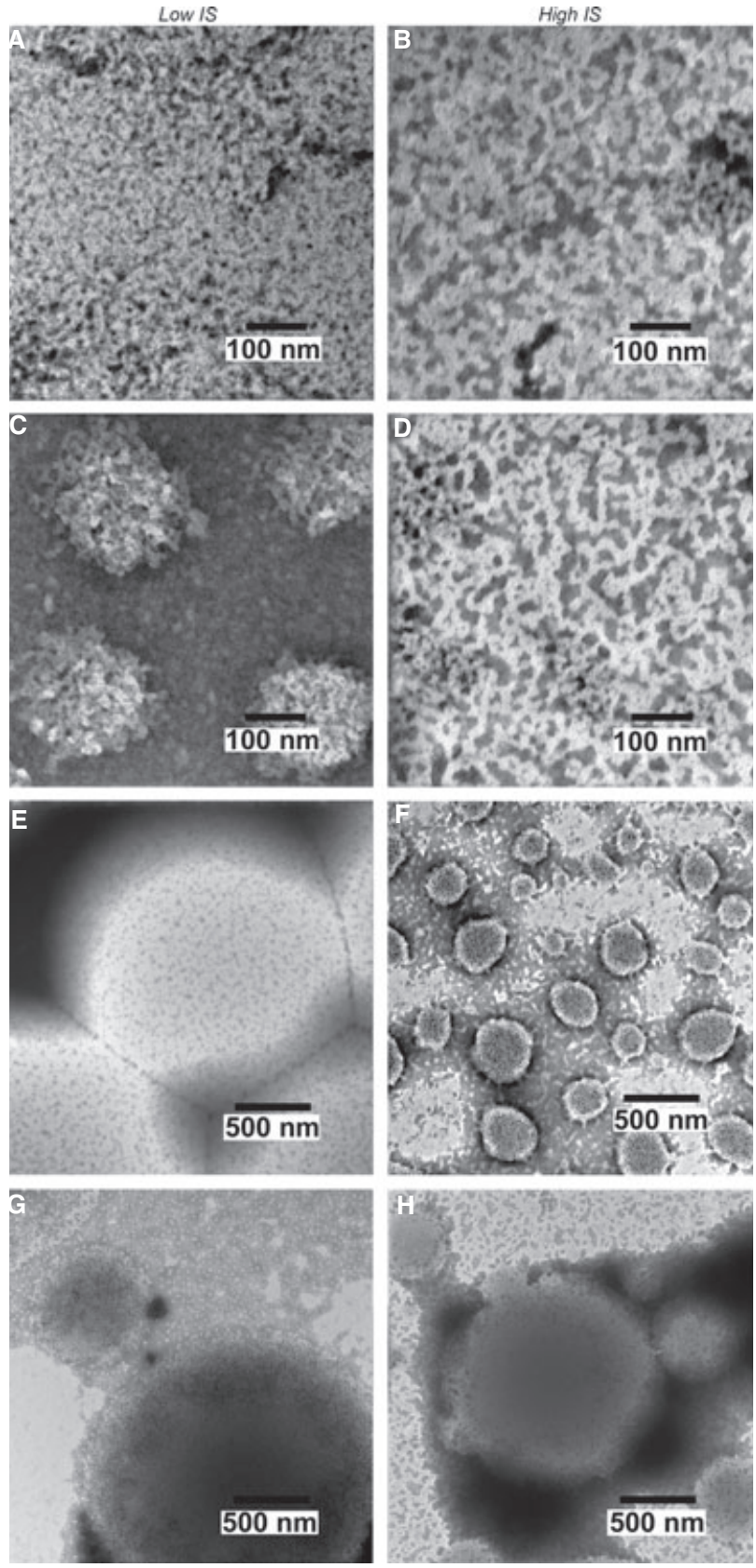

Fig. 6. Transmission electron microscopy (TEM) images with phospho-tungstic acid (PTA) staining of amelogenins $\left(2 \mathrm{mg} \mathrm{ml}^{-1}\right)$ in the presence of $2.5 \mathrm{mM}$ calcium: P173 (A), rP172 (C), P148 (E), and $\mathrm{rP} 147(\mathrm{G})$ at low ionic strength $(\mathrm{IS}=7.5 \mathrm{mM}$ ) and P173 (B), rP172 (D), P148 (F), and rP147 $(\mathrm{H})$ at high ionic strength (IS $=162 \mathrm{mM}$ ).

P148, stabilize ACP for long periods of time in vitro and prevent its transformation to HA at low IS. This effect was found to be associated with the presence of the single phosphate group in native amelogenins. The ability of native amelogenins to stabilize ACP in vitro is consistent with recent findings which have clearly shown that linear arrays of ACP are initially formed in secretory enamel before their subsequent transformation to apatitic crystals of similar morphology (13). 
The present study was carried out to extend this previous work by examining the effect of native and recombinant amelogenins on mineralization under experimental conditions that more closely reflect those found in vivo during the initial stages of enamel formation. Hence, studies were carried out to compare previous findings obtained at low IS (i.e. $10 \mathrm{mM}$ ) with findings obtained in the present study under conditions of higher IS (i.e. $162 \mathrm{mM}$ ) similar to that found in secretory enamel fluid (20). For comparative purposes, the concentrations of calcium, phosphate, and protein, as well as the initial $\mathrm{pH}$, were the same as in the previous studies carried out at lower IS. It should be noted, however, that although the mineral ion composition remains the same, the high-IS solution has a calculated degree of saturation (as defined in 29) with respect to HA $\left(\mathrm{DS}_{\mathrm{HA}}\right)$ that is lower (IS $\left.=162 \mathrm{mM}, \mathrm{DS}_{\mathrm{HA}}=25.9\right)$ than that for the low-IS solution (IS $=10 \mathrm{mM}$, $\left.\mathrm{DS}_{\mathrm{HA}}=42.6\right)$. Despite this difference in $\mathrm{DS}_{\mathrm{HA}}$, in the absence of amelogenin (control), high-IS conditions (and lower $\mathrm{DS}_{\mathrm{HA}}$ ) induced the spontaneous formation of calcium phosphate crystals in vitro in the same manner and at a comparable rate to that previously observed at low IS $(8,17)$. Notably, under both sets of conditions, calcium phosphate crystallization proceeded through the initial formation of ACP and its subsequent transformation to randomly arranged plate-like HA crystals (Fig. 3). Thus, the predominant variable in the present study is IS and not the rate of mineralization.

As seen with the control, the effects of rP172, rP147, and P173 on mineralization at high IS were found to be essentially the same as those observed previously at low IS. Hence, under high-IS conditions, rP172 was again found to transiently stabilize ACP nanoparticles and guide their alignment into linear arrays during the formation of ordered bundles of needle-like HA crystals in vitro (Fig. $4 \mathrm{~A}-\mathrm{C}$ ). This capacity has been attributed to the ability of rP172 to form chain-like protein assemblies (e.g. 17) under near-neutral $\mathrm{pH}$ conditions. In the present study, DLS and TEM findings suggest that IS has a small influence on rP172 assembly in the presence of calcium, with somewhat larger rP172 aggregates seen at low IS (Table 1). The observed effect of IS and added calcium on protein aggregation, noted in this study, may also be related to a difference in the free calcium activities for the low-IS (1.75 mM) and high-IS (0.82 mM) solutions. On this basis, additional studies are needed to better understand the effect of calcium concentration (or activity) on amelogenin assembly.

Ionic strength was also found to have little impact on the effect of rP147 on mineralization. rP147, which lacks the hydrophilic C-terminus, once again exhibited little influence on HA formation, forming randomly arranged thin plate-like HA crystals (Fig. 4D-F), similar to those seen in the control and found previously at low IS (8). A tendency for the more hydrophobic rP147 to form large aggregates was also observed at both low IS and high IS, in the presence and absence of added calcium. Furthermore, at a high IS, the full-length native (phosphorylated) amelogenin P173 was found to stabilize ACP formation and prevent its transformation to HA for up to $48 \mathrm{~h}$, as was previously found at low IS (17). Although it is interesting to note that the addition of calcium resulted in enhanced P173 aggregation at low IS, with a similar, but smaller, effect being observed for rP172, DLS revealed that added calcium had no effect on the aggregation of either full-length protein at high IS. Nevertheless, a marked difference in IS had little influence on the observed effect of either P173 or rP172 on spontaneous calcium phosphate formation.

In sharp contrast to observations for the other proteins studied, particularly P173, increased IS had a notable influence on the effect of P148 on mineralization. Unlike the findings at low IS (8), P148 exhibited a diminished capacity to prevent the transformation of initially formed nanoparticles of ACP to crystalline HA at high IS, in contrast to what was seen with P173. The lessened ability of P148 to inhibit ACP transformation to HA at higher IS may be related to an enhanced stabilization of smaller aggregates of P148 in solution, as a result of greater charge shielding under high-IS conditions [see (30) for background discussion] that could reduce protein interactions with ACP. Consistent with this idea, smaller and more isolated aggregates of P148 in the presence of calcium at high IS were observed (Fig. 6F). Based on the present findings, IS appears to reduce slightly the capacity of P148 to interact with initially formed (ACP) mineral phases, allowing phase transformation to HA to take place slowly. The effect of IS on the stability of protein assemblies may be particularly important for P148 as it is significantly more hydrophobic than the full-length P173, which tends to form much less aggregated chain-like structures in solution under either low-IS or high-IS conditions (present study, 17).

During the transformation of ACP to HA, however, it is nevertheless apparent that phosphorylated P148 can interact with developing HA crystals, while its nonphosphorylated analog, rP147, does not. P148 was found to exhibit a capacity to regulate the shape and possibly the organization of forming HA crystals, although the effects observed were quite variable. The observed variability may further suggest that P148 is simply not a very effective regulator of the ACP to HA transformation process, for example, in comparison to that observed for full-length amelogenin rP172 (8). Consistent with this idea, P148 has been shown to have a much lower adsorption affinity for HA than does rP172 (31). However, based on a comparison of the results reported here on the effect of rP147 on calcium phosphate formation, the presence of the single phosphate group in P148 appears to have a significant influence on proteinmineral interactions at high IS. Randomly arranged HA plate-like crystals, similar to those seen in the control, were formed in a matter of minutes in the presence of rP147, while needle-like crystals (albeit of varying sizes) formed slowly in the presence of P148 within a 24-h period. Consequently, unlike its non-phosphorylated form, P148 exhibits a capacity to regulate the rate of formation and shape of HA crystals, possibly through preferential adsorption and inhibition of growth in directions perpendicular to the long axis ( $c$-axis) of HA. 
It should be noted, with the possible exception of rP147, that findings for the full-length amelogenins and native P148 were also obtained under physiological $\mathrm{pH}$ conditions that are similar to those found [mean $\mathrm{pH} \pm$ $\mathrm{SE}=7.26 \pm 0.04]$ in secretory enamel fluid (20). Overall, IS was found to have a lesser impact on the regulation of mineralization by amelogenins than other noted factors such as phosphorylation and the presence of the hydrophilic C-terminus.

In conclusion, under the high-IS conditions found in developing enamel, P148 has been shown to be less effective than $\mathrm{P} 173$ in preventing ACP transformation to HA. Differences observed under physiological conditions of IS and $\mathrm{pH}$ suggest that P173 and P148 may play different roles in regulating early enamel mineral formation. Based on noted differences in the effects on mineralization, the present data support the notion that additional processing of full-length amelogenin may be required in vivo to induce the transformation of initially formed ACP phases to apatitic enamel crystals, as suggested through processes of proteolytic degradation $(15,16)$ and dephosphorylation (32).

Acknowledgements - This work was supported by grants R01DE016376 (HCM) and T32-DE007327 from the National Institute of Dental and Craniofacial Research.

Conflicts of interest - The authors declare that there are no conflicts of interest with respect to this manuscript.

\section{References}

1. Fukae M, Yamamoto R, Karakida T, Shimoda S, Tanabe T. Micelle structure of amelogenin in porcine secretory enamel. $J$ Dent Res 2007; 86: 758-763.

2. Sмітн CE. Cellular and chemical events during enamel maturation. Crit Rev Oral Biol Med 1998; 9: 128-161.

3. Fincham AG, Moradian-Oldak J, Simmer JP. The structural biology of the developing dental enamel matrix. J Struct Biol 1999; 126: 270-299.

4. Magolis HC, Beniash E, Fowler CE. Role of macromolecular assembly of enamel matrix proteins in enamel formation. $J$ Dent Res 2006; 85: 775-793.

5. IiJima M, Moradian-Oldak J. Interactions of amelogenins with octacalcium phosphate crystal faces are dose dependent. Calcif Tissue Int 2004; 74: 522-531.

6. Wen HB, Moradian-Oldak J, Zhong JP, Greenspan DC, FINCHAM AG. Effects of amelogenin on the transforming surface microstructures of Bioglass in a calcifying solution. $J$ Biomed Mater Res 2000; 52: 762-773.

7. Beniash E, Simmer JP, Margolis HC. Effects of recombinant mouse amelogenins on the formation and organization of hydroxyapatite crystals in vitro. J Struct Biol 2005; 149: 182190.

8. Kwak SY, Wiedemann-Bidlack FB, Beniash E, Yamakoshi Y, Simmer JP, Litman A, Margolis HC. Role of $20 \mathrm{kDa}$ amelogenin (P148) phosphorylation in calcium phosphate formation in vitro. J Biol Chem 2009; 284: 18972-18979.

9. Posner AS, Betts F. Synthetic amorphous calcium phosphate and its relation to bone mineral structure. Acc Chem Res 1975; 8: 273-281.

10. Boskey AL. Amorphous calcium phosphate: the contention of bone. J Dent Res 1997; 76: 1433-1436.

11. Termine JD, Posner AS. Infrared analysis of rat bone-age dependency of amorphous and crystalline mineral fractions. Science 1966; 153: 1523-1525.
12. WEINER S. Transient precursor strategy in mineral formation of bone. Bone 2006; 39: 431-433.

13. Beniash E, Metzler RA, Lam RS, Gilbert PUPA. Transient amorphous calcium phosphate in forming enamel. $J$ Struct Biol 2009; 166: 133-143.

14. Robinson C, Fuchs P, Weatherell JA. The appearance of developing rat incisor enamel using a freeze fracturing technique. J Cryst Growth 1981; 53: 160-165.

15. Robinson C, Shore RC, Wood SR, Brookes SJ, Smith DAM, WRIGHT JT. Subunit structures in hydroxyapatite crystal development in enamel: Implications for amelogenesis imperfecta. Connect Tissue Res 2003; 44: 65-71.

16. Robinson C. Self-oriented assembly of nano-apatite particles: a subunit mechanism for building biological mineral crystals. $J$ Dent Res 2007; 86: 677-679.

17. Wiedemann-Bidlack FB, Kwak Sy, Beniash E, Yamakoshi Y, Simmer JP, MARGOLIS HC. Effects of phosphorylation on the self-assembly of native full-length porcine amelogenin and its regulation of calcium phosphate formation in vitro. $J$ Struct Biol 2011; 173: 250-260.

18. Le Norcy E, Kwak SY, Wiedemann-Bidlack FB, Beniash E, Yamakoshi Y, Simmer JP, Margolis HC. Potential role of the amelogenin $\mathrm{N}$-terminus in the regulation of calcium phosphate formation in vitro. Cells Tissues Organs 2011; 194: 188-193.

19. Le Norcy E, Kwak SY, Wiedemann-Bidlack FB, Beniash E, YAmakoshi Y, Simmer JP, Margolis HC. Leucine-rich amelogenin peptides regulate mineralization in vitro. $J$ Dent Res 2011; 90: 1091-1097.

20. Aoba T, Moreno EC. The enamel fluid in the early secretory stage of porcine amelogenesis: chemical composition and saturation with respect to enamel mineral. Calcif Tissue Int 1987; 41: 86-94.

21. Yamakoshi Y, Tanabe T, Fukae M, Shimizu M. Porcine amelogenins. Calcif Tissue Int 1994; 54: 69-75.

22. Ryu OH, Fincham AG, Hu CC, Zhang C, Qian Q, Bartlett JD, SimMER JP. Characterization of recombinant pig enamelysin activity and cleavage of recombinant pig and mouse amelogenins. J Dent Res 1999; 78: 743-750.

23. EANES ED. Octacalcium phosphate. In: CHOW LC, EANES ED, eds. Monographs in Oral Science. Vol. 18. Basel: Karger AG, 2001; 130-147.

24. Mahamid J, Sharir A, Addadi L, Weiner S. Amorphous calcium phosphate is a major component of the forming fin bones of zebrafish: indications for an amorphous precursor phase. Proc Natl Acad Sci USA 2008; 105: 12748-12753.

25. Ofir PB, Govrin-LipPman R, Garti N, Furedi-Milhofer H. The influence of polyelectrolytes on the formation and phase transformation of amorphous calcium phosphate. Cryst Growth Des 2004; 4: 177-183.

26. Tao J, PAN H, Zeng Y, Xu X, TANG R. Roles of amorphous calcium phosphate and biological additives in the assembly of hydroxyapatite nanoparticles. J Phys Chem B 2007; 111: 1341013418.

27. Deshrande AS, Fang PA, Simmer JP, Margolis HC, Beniash E. Amelogenin-collagen interactions regulate calcium phosphate mineralization in vitro. J Biol Chem 2010; 285: $19277-$ 19287.

28. Dey A, Bomans PHH, Muller FA, Will J, Frederik PM, Dewith G, SommerdiJkKk NAJM. The role of prenucleation clusters in surface-induced calcium phosphate crystallization. Nat Mater 2010; 9: 1010-1014.

29. Moreno EC, Margolis HC. Composition of human plaque fluids. J Dent Res 1988; 67: 1181-1189.

30. Luey JK, Mcguire J, Sproull RD. The effect of $\mathrm{pH}$ and $\mathrm{NaCl}$ concentration on adsorption of $\beta$-lactoglobulin at hydrophilic and hydrophobic silicon surfaces. J Colloid Interface Sci 1991; 143: 489-500.

31. Moradian-Oldak J, Bouropoulos N, Wang L, GharakhaNIAN N. Analysis of self-assembly and apatite binding properties of amelogenin proteins lacking the hydrophilic C-terminal. Matrix Biol 2002; 21: 197-205.

32. Brookes SJ, Kirkham J, Shore RC, Bonass WA, Robinson C. Enzyme compartmentalization during biphasic enamel matrix processing. Connect Tissue Res 1998; 39: 89-99. 


\section{Supporting Information}

Additional Supporting Information may be found in the online version of this article:

Fig. S1. FT-IR spectra of calcium phosphate minerals produced at high IS.

Fig. S2. TEM images of minerals formed in the presence of P148.
Fig. S3. SAED patterns of carbon-coated $\mathrm{Cu}$ grid (A) and synthetic ACP (B).

Fig. S4. Conventional FT-IR spectrum of synthetic ACP.

Please note: Wiley-Blackwell is not responsible for the content or functionality of any supporting materials supplied by the authors. Any queries (other than missing material) should be directed to the corresponding author for the article. 